\title{
Prosthetic Valve Thrombosis
}

National Cancer Institute

\section{Source}

National Cancer Institute. Prosthetic Valve Thrombosis. NCI Thesaurus. Code C50709.

The formation of a blood clot that is attached to or near an artificial heart valve; this can cause dysfunction of the valve, and possibly lead to an embolic event should the thrombus become dislodged. 